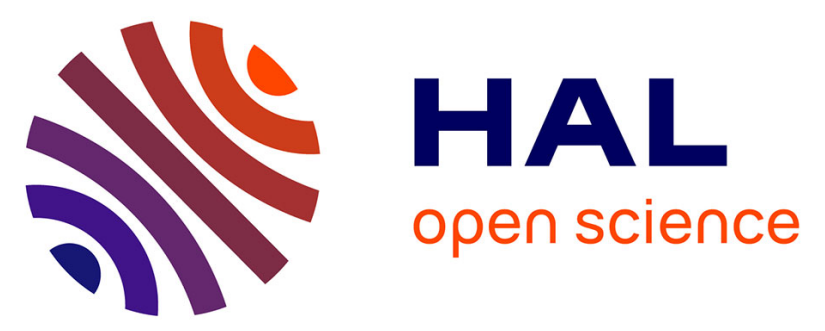

\title{
Regulation of the switch from myometrial contractures to contractions in late pregnancy: studies in the pregnant sheep and monkey
}

P.W. Nathanielsz, D.A. Giussani, C.A. Mecenas, W. Wu, J.A. Winter, Rafael

Garcia Villar, M. Baguma-Nibasheka, M.B.O.M. Honnebier, T.J. Mcdonald

\section{To cite this version:}

P.W. Nathanielsz, D.A. Giussani, C.A. Mecenas, W. Wu, J.A. Winter, et al.. Regulation of the switch from myometrial contractures to contractions in late pregnancy: studies in the pregnant sheep and monkey. Reproduction, Fertility and Development, 1995, 7, pp.595-602. hal-02706946

\section{HAL Id: hal-02706946 \\ https://hal.inrae.fr/hal-02706946}

Submitted on 1 Jun 2020

HAL is a multi-disciplinary open access archive for the deposit and dissemination of scientific research documents, whether they are published or not. The documents may come from teaching and research institutions in France or abroad, or from public or private research centers.
L'archive ouverte pluridisciplinaire HAL, est destinée au dépôt et à la diffusion de documents scientifiques de niveau recherche, publiés ou non, émanant des établissements d'enseignement et de recherche français ou étrangers, des laboratoires publics ou privés.

\section{()(1)(2)}

Distributed under a Creative Commons Attribution - ShareAlikel 4.0 International 


\title{
Regulation of the Switch from Myometrial Contractures to Contractions in Late Pregnancy: Studies in the Pregnant Sheep and Monkey
}

\author{
Peter W. Nathanielsz, Dino A. Giussani, \\ Charles A. Mecenas, Wen Wu, James A. Winter, \\ Rafael Garcia-Villar, Mark Baguma-Nibasheka, \\ M. Barbera O. M. Honnebier and T. J. McDonald \\ Laboratory for Pregnancy and Newborn Research, Depariment of Physiology, College \\ of Veterinary Medicine, Cornell University, Ihaca, NY 14853-6401, USA.
}

\begin{abstract}
Myometrial contractility occurs throughout pregnancy and characteristic patterns of myometrial activity exist according to the endocrine status and the relationship to parturition. These characteristic patterns differ between species, yet certain common features can be observed. Throughout pregnancy, myometrial activity is of the contractures type, long-lasting, low-amplitude epochs of activity switching to contraction-type activity at term. This switch from contractures to contractions tends to occur at night and is related to alteration in maternal plasma oestrogen concentrations, and maternal oxytocin function. Studies in several animal species support the hypothesis that maternal oestrogen prepares the myometrium for a periodic signal that causes the switch from contractures to contractions. Several lines of evidence implicate oxytocin in the switch. These studies show that the detailed preparation for parturition takes longer than previously considered and is brought about by a carefully regulated sequence of events in which oestrogen production by the placenta plays a central role.
\end{abstract}

\section{Introduction}

Geoffrey Thorburn is one of the original pioneers of the experimental study of the physiology of both mother and fetus over the whole duration of pregnancy. His research has been a stimulus to all of us who wish to understand the multiple regulatory mechanisms that bring about parturition. His classic studies on ovarian function, fetal and placental endocrinology, myometrial contractility, and placental function have been an inspiration to many investigators at all stages of their own scientific development. His ideas, generously disscminated to all, have been the stimulus to many experiments conducted by researchers throughout the world. It gives us great pleasure to review here some of our own work in the field of pregnancy physiology which was presented at a symposium in honour of Geoffrey Thorburn. We shail focus on the regulation of patterns of myometrial contractility that occur throughout pregnancy. We have increasingly used the comparative approach, particularly in comparing the patterns of myometrial activity that occur throughout pregnancy in sheep and non-human primates. The marked inter-species differences in the characteristics of myometrial activity are likely to provide key information on regulatory mechanisms that are critical and rate limiting as distinct from those mechanisms that are simply supportive of the process of parturition once it has been initiated.

\section{Regulation of Myometrial Contractility during Pregnancy.}

In any investigation of myornetrial activity throughou pregnancy and the changes that lead to successful parturition, it is necessary to use invasive techniques to track and characterize the different patterns of myometrial activity observed in pregnant experimental animals. At the present time, it is not possible to rccord subtle changes in myometrial function throughout pregnancy in pregnant women. We have demonstrated clear differences in the pregnant primate (Taylor et al. 1983; Hsu et al. 1989) and pregnant sheep (Jansen et al. 1979; Nathanielsz et al. 1980; Harding et al. 1982; Binienda et al. 1989) between two types of myometrial activity, contractures and contractions (Fig. 1). Contractures are long-lasting epochs of electrical and contractile activity of the myometrium that occur throughout pregnancy (Fig. 1a). Contractions are short-lived epochs accompanied by greater contractile force (Fig. 1b). In addition to measuring individual epochs of myometrial activity, we have undertaken fast fourier transformation of the patterns of myometrial activity observed with either myometrial electromyographic(EMG) recordings or intrauterine pressure (IUP). The power spectra shown in Fig. 1 clearly identified whether the myometrium is contracting in the contractures mode or the contractions mode. The units of amplitude of the power spectrum are consistent within an animal but depend on 
(a) Uterus in contracture mode
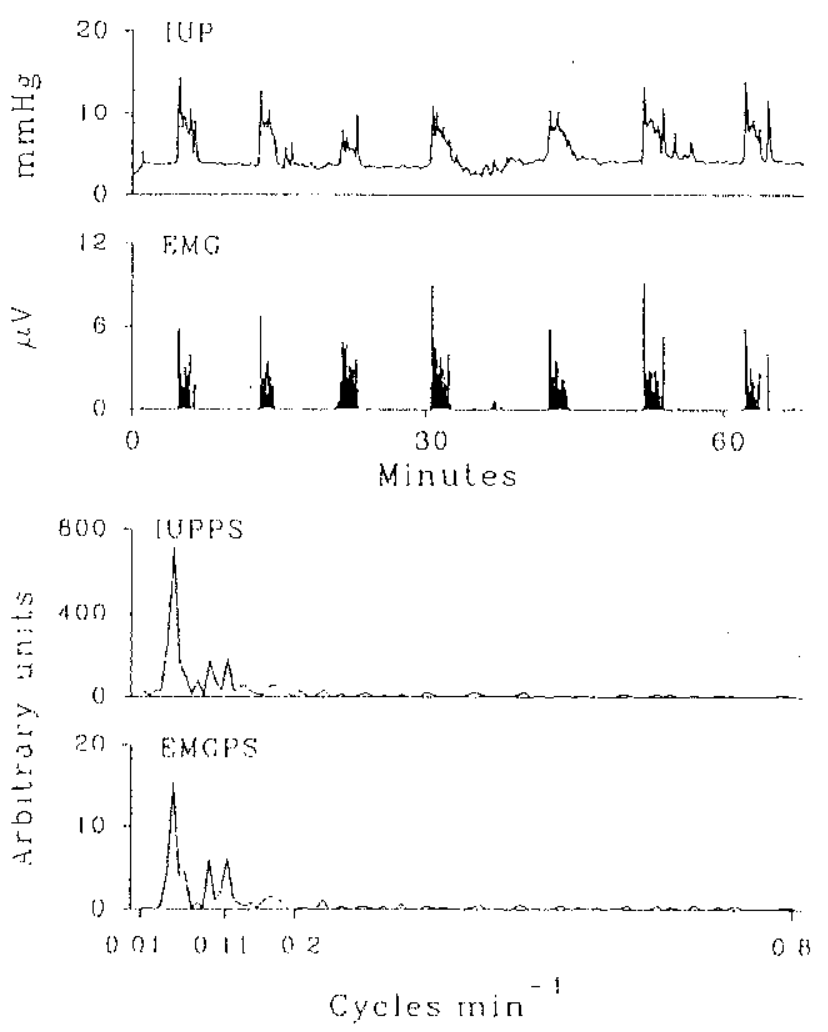

(b) Uterus in contractions mode
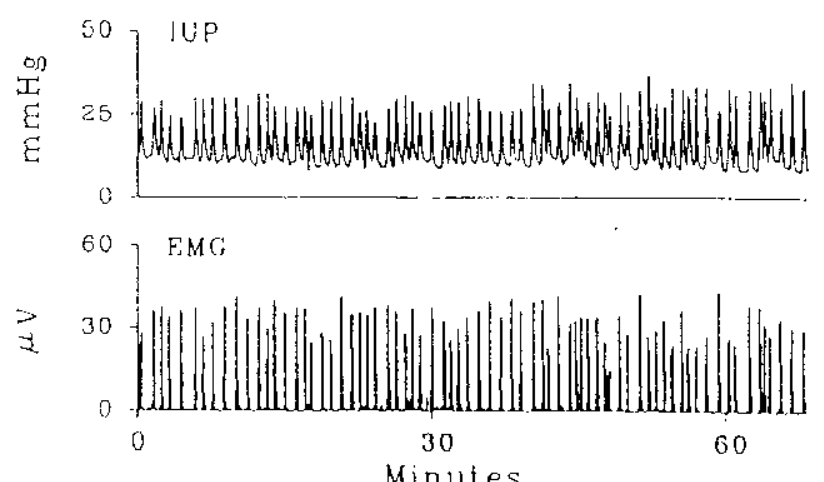

Minutes

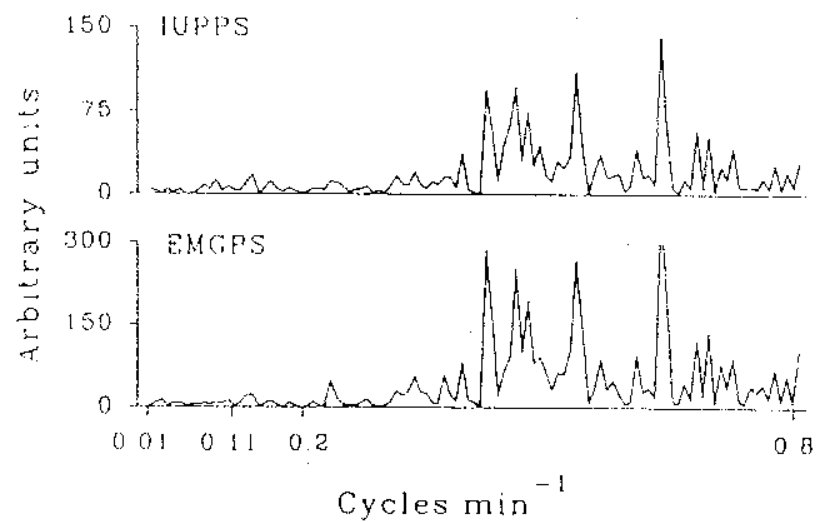

Fig. 1. Recordings from the utens of a pregnant rhesus monkey in (a) contracture mode and (b) contractions mode. IUP, intrauterine pressure; EMG, uterine electromyogram; IUPPS, power spectral analysis of ILP; EMGPS, power speciral analysis of EMG.

the amplitude of the signal obtained. Since, particularly with the EMG, the signal depends on the exact site of the uterus from which the signal has been obtained, the units are arbitrary and depend on the efficicncy with which the electrodes record the signal. However, since the electrodes remain in the same location throughout the study, changes from hour to hour or day to day in a particular animal can be followed with great accuracy. The advantage of using power spectral analysis is that it permits quantitication of activity and retains the qualitative lcature of high-frequency contractions or infrequent, longlasting contractures. The application of power spectral analysis to recording of myometrial activity using both EMG and IUP methods (Hsu et al. 1989) permits quantification of these distinct types of activity under different situations such as food withdrawal (Binicnda et al. 1989) and stimulation of vestrogen produclion by the infusion of androgen precursors (Figueroa et al. 1989). The central hypothesis of our recent studies is that ocstrogen constitutes the critical and indispensable link between fetal (and maternal) androgen production and the stimulation of the cascade of events that eventually lead, by the recruitment of many positive feed-forward systems, " to the three indispensable features of normal labour and delivery - namely, membrane rupture, cervical dilatation and efficient myometrial contractility. In this review, we focus on the regulation of myometrial contractility.

Maternal plasma oestrogen concentrations rise in late pregnancy in the human (Buster et al. 1979), in the rhesus monkey (Novy and Waish 1981), and in the sheep (Challis 1971). Oestrogen stimulates several of the key features that will convert contractures to contractions: increased oxytocin production (Zhang et al. 1991); increased oxytocin receptor availability, and sensitivity of the uterus in the rat (Soloff et al. 1982) but not in ovine tissue explants (Sheldrick and Flick-Smith 1993); and increased prostaglandin synthesis (Zhang et al. 1991). Infusion of androstenedione into the pregnant rhesus monkey for $48 \mathrm{~h}$ results in the switch of contractures to contractions (Figueroa et al. 1989). We chose androstenedione as the oestrogen precursor 10 infuse in order to elevate maternal plasma oestrogen concentrations. Novy and Walsh (1981) had previously demonstrated that androstenedione is a very efficient vestrogen precursor when administered intravascularly to the maternal circulation in the pregnant rhesus monkey. Androstenedione has also been used as a precursor for ocstrogen production in the baboon. (Albrecht and Pepe $1990)$.

In studies with the pregnant monkey, we developed a regimen in which androstenedione was infused into the maternal circulation at a rate that produced the 


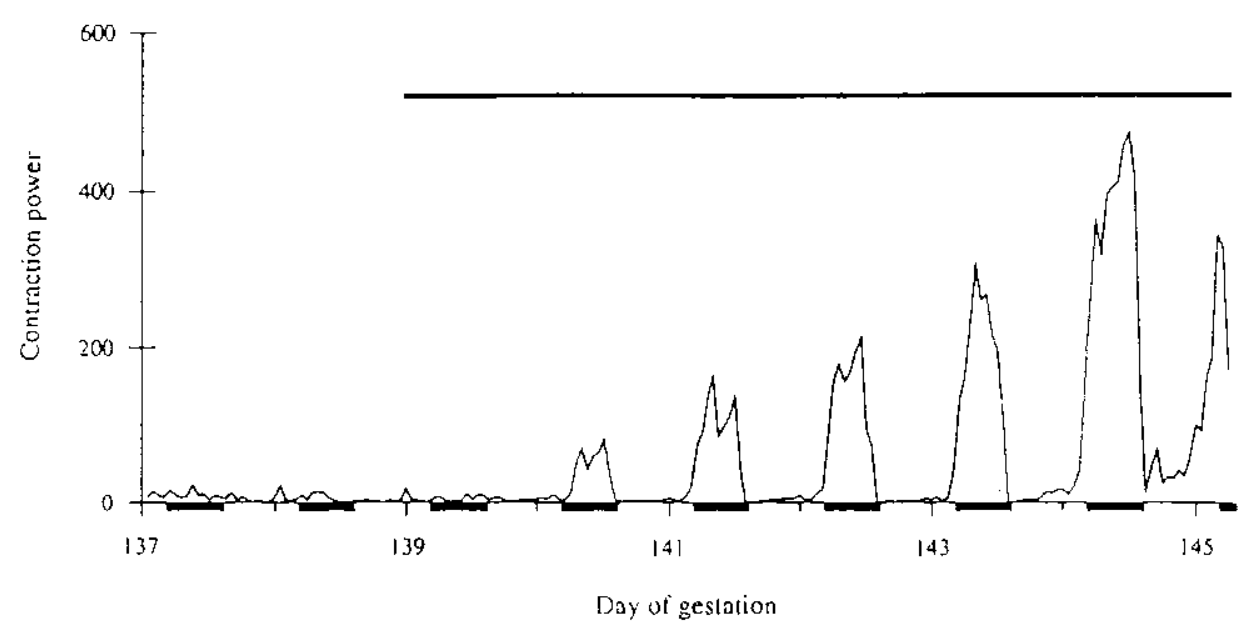

Fig. 2. Contraction power in the uterine electromyogram in a rhesus monkey infused continuousiy $(0 \cdot 3 \mathrm{mg}$ $\mathrm{kg}^{-1} \mathrm{~h}^{-1}$ ) with $\Delta^{4}$-androstenedione (period of infusion indicated by upper solid line). Contraclions occur during the hours of darkness (represented by lower solid lines) and increase nightly until delivery at 145 days gestation.

normal physiological rise in oestrogen concentration observed at term (an increase to plasma concentrations of approximately $1500 \mathrm{pg} \mathrm{mL}^{-1}$ ) (Figueroa et al. 1989), It was of considerable interest that, although this 24 -h infusion of androstenedione maintains elevated oestrogen concentration in the maternal plasma for the full 24-h day, the switch from contractures to contractions occurred only at night (Fig. 2). This pattern of myometrial activity corresponds to the normal $24-h$ periodicity that occurs in the switch of the myometrial activity pattern in parturition at term (Ducsay et al. 1983; Taylor et al. 1983). Prolonging the androstenedione infusion for several hours will lead to apparently normal labour and delivery of a viable fetus (Mecenas et al. 1994). Thus, androgen infusion accompanied by no other experimental perturbation leads to the normal myometrial patterns at term, adequate ccrvical dilatation and rupture of the fetal membranes (Fig. 2). The importance of infusing androstenedione precursor rather than oestrogen itself is demonstrated by the failure of other investigators to precipitate premature delivery in the rhesus monkey by the intravascular administration of oestrogen in concentrations that raised maternal plasma oestrogen concentrations 23 -fold higher than values normally seen in the peripheral circulation at the end of gestation (Hotchkiss et al. 1982; Novy and Walsh 1983). Recently, we confirmed the observation that intravenous administration of oestrogen to the maternal circulation will cause the repetitive switch from contractures to contractions but not the other changes associated with labour and delivery ( $P$. W. Nathanielsz, D. A. Giussani and C. A. Mecenas, unpublished data). This difference between the effects of peripheral vascular administration of androgen and oestrogen suggests that oestrogen plays a role, in part, by local paracrine mechanisms at, or very near to, its sitc of production within the placenta and fetal membranes where local oestrogen concentrations are likely to be higher than those achieved in the peripheral circulation. Oestrogen in the peripheral circulation may not obtain adequate and efficient access to the critical cellular mechanisms required to switch contractures to contractions.

The central role of oestrogen has been further supported by elegant studies by Wilson et al. (1991) in the pregnant baboon, in which the profile of the maternal plasma oestrogen concentration has been shown to shift in the late hours of the aftemoon so that the oestrogen:progesterone ratio rises in the last 10 days of pregnancy. This shift in profile may represent altered contributions of androgen from mother and fetus for placental aromatization resulting in differing rates of production of oestrogen at different times of the day in late gestation. Alternatively, the gradual earlier rise in maternal plasma oestrogen concentrations in the afternoon as parturition approaches may simply reflect increased availability of androgen precursor from the fetal adrenal with a consequent earlier increase in the absolute values. In addition, Wilson et al. (1994) adapted the androgen-infused model we have used in the rhesus monkey to the pregnant baboon. They demonstrated that infusion of the androgen dehydroepiandrosterone sulfate (DHEAS) to the pregnant baboon led to a switch from contractures to contractions. Using this paradigm, they demonstrated that inhibition of the conversion of androgen to oestrogen by aromatase inhibitors also prevents the switch in myometrial contraction patterns (Wilson et al. 1994). Thus, it is unlikely that a direct action of androgens produced either from a maternal or fetal 
source, is capable, by itself, of initiating the critical changes in myometrial activity that occur at the time of labour and delivery.

A final observation that indicates the central role of oestrogen is a consideration of the species differences in the timing of the increase in maternal plasma oestrogen that occurs at term. In the pregnant sheep, the rise in maternal plasma oestrogen concentration is very abrupt, occurring only during the last 24 h of pregnancy (Challis 1971) in contrast to non-human primates in which the rise is gradual over several days to weeks (Novy and Walsh 1981). This rapid increase in maternal plasma oestrogen concentration, occurring as it does over a single day, explains the observation that sheep contractures switch to contractions only once, about $6 \mathrm{~h}$ before delivery (Fig. 3). In contrast, in pregnant rhesus monkeys maternal plasma oestrogen concentration increases over several days before delivery, As a result, the switch from contractures 10 contractions repeats each night for several nights before delivery (Fig. 4). The cause of this difference in the timing of the rise in oestrogen concentration in late gestation to labour and delivery between sheep and primates is of great interest and remains to be elucidated.

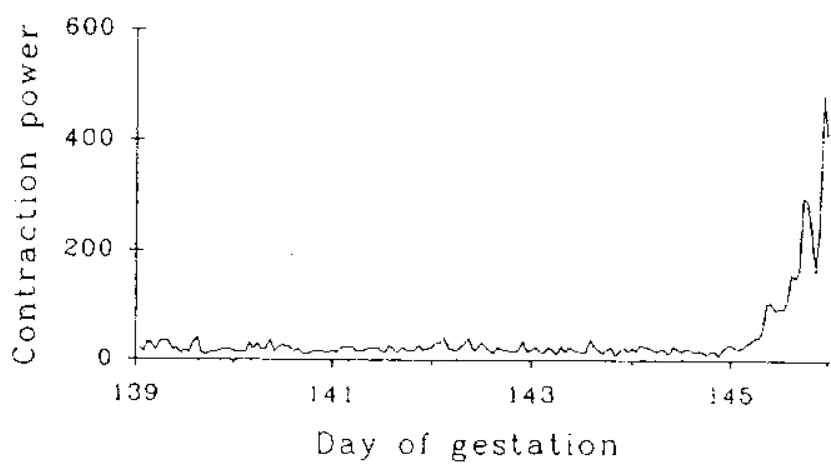

Fig. 3. Contraction power in the uterine electromyogram in a sheep delivering spontaneously at term.

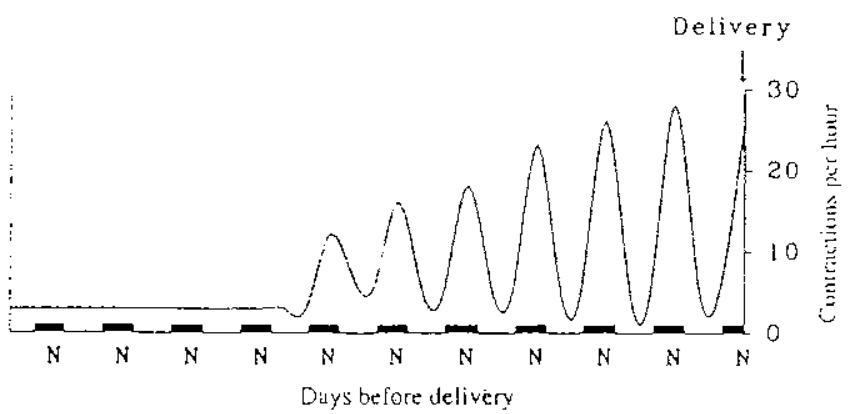

Fig. 4. Repetitive switch from contractures to contractions 7 nights before delivery in a pregnant rhesus monkey. When the monkey had no coniractions, myometrial activity was solely of the contractures lype. N, night, hours of darkness. Reproduced with permission from Nathanielsz (1992).
In primates, the normal source of the increased androgen production at term is most likely to be the fetal adrenal. In addition, some androgen is produced by the maternal adrenal. In sheep, it is very clear that the fetal hypothalamo-pituitary-adrenal axis initiates the rise in cortisol concentration that results in induction of placental enzymes that convert progesterone to oestrogen (Liggins et al. 1973; Anderson et al. 1975; McDonald and Nathanielsz 1991; Nathanielsz 1992; Nathanielsz et al. 1992). Data from Serón-Ferré and colleagues shows that, in the pregnant rhesus monkey, there is an increase in the concentration of fetal DHEAS which very closely parallels the dramatic rise in fetal plasma cortisol concentration that occurs in sheep over the final 15\% of pregnancy (see review by Nathanielsz 1992). Thus, the time frame of the increase in the concentration of DHEAS in the non-human primate and cortisol in the fetal sheep bear considerable resemblance to each other (Nathanielsz 1992) (Fig. 5).

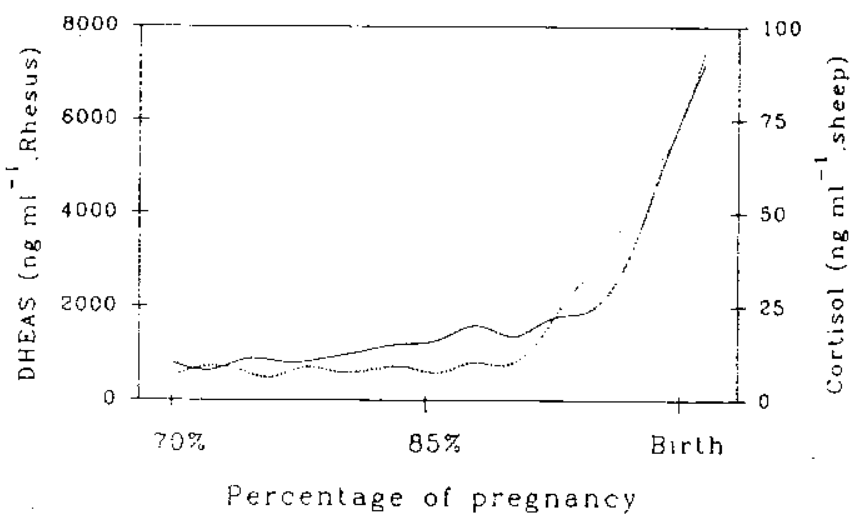

Fig. 5. Similarities in the rise in the concentration of fetal dehydroepiandrosterone sulfate (DHEAS; ...) in the rhesus monkey and fetal cortisol (-) in sheep over the last $20 \%$ of gestation. Reproduced with permission from Nathanielsz (1992).

In the sheep, lesions of the fetal paraventricular nucleus (McDonald and Nathanielsz 1991), fetal hypophysectomy (Liggins et al. 1973), and adrenalectomy (Liggins et al. 1973) will all prolong pregnancy. In the monkey, it is not possible to undertake such studies with ease, since any form of intrauterine surgery tends to lead to premature labour. However, we have demonstrated that fetectomy in the pregnant rhesus monkey will prolong pregnancy (Nathanielsz et al. 1992). This study confirms the findings of Lanman et al. (1975) and contradicts those of Van Wagenen and Newton (1943). The discrepancy between these various studies is of great importance. Van Wagenen and Newton (1943) studied pregnancies in which the fetus was removed at gestational ages from 70 days to 157 days gestation. In addition, several of their animals were treated with varying doses of steroids at different times in pregnancy rendering any firm conciusion extremely difficult. 
The experimental evidence presented so far suggests that oestrogen, produced as a result of activity of the fetal hypothalamo-pituitary-adrenal axis stimulates the switch in myometrial activity from contractures to contractions. However, oestrogen may also play a role in the maturation of the fetal hypothalamo-pituitary-adrenal axis itself. Albrecht and Pepe have proposed the hypothesis that, under normal circumstances in primate pregnancy, placental $11 \beta$-hydroxysteroid dehydrogenase ( $11 \beta$-HSD) activity is low, thus maternal cortisol freely passes across the placenta, accesses the fetal circulation, and is able to inhibit the fetal hypothalamo-pituitary-adrenal axis by negative feedback (Albrecht and Pepe 1990; Pepe and Albrecht 1990). According to this hypothesis, in late gestation under the influence of oestrogen, placental $11 \beta$-HSD activity is stimulated, cortisol is converted to cortisone, and this negative feedback is lost, thereby permitting increased activity of the fetal hypothalamopituitary-adrenal axis with increased androgen production.

This hypothesis is attractive and probably plays an important role in the mechanisms responsible for activation of the fetal hypothalamo-pituitary-adrenal axis in the nonhuman primate fetus. Further experimental information is required on the exact timing relationship of the changes in oestrogen production, placental $11 \beta$-HSD activity, and fetal adrenal androgen secretion throughout the final third of gestation in the baboon and other primates, including pregnant women.

Marked 24-h rhythms have been demonstrated in matemal plasma steroid concentrations in pregnant monkeys (Walsh et al. 1984), baboons (Wilson et al. 1991), and women (Patrick et al. 1980). These 24-h changes in steroid profiles suggest a mechanism for the 24-h rhythm in the switch from contractures to contractions. However, a temporal relationship between two processes does not necessarily give any indication of causation between the two processes. It may be that they both reflect a third and independent process which governs them both. The 24-h periodicity of the switching of contractures to contractions during constant androstenedione infusion to the mother (Fig. 2), despite clevated oestrogen concentrations throughout the 24-h day, suggests that oestrogen may lower the threshold required for the firing of some pre-existing clock.

The issue of the role of oxytocin in the initiation of labour is an excellent example of changing scientific fashions and altered concepts. In the 1950s and $1960 \mathrm{~s}$, several investigators favoured the view that oxytocin was a key initiator of the process of labour and delivery (Theobald 1969). However, a clear demonstration of increased circulating peripheral concentrations of oxytocin before, as distinct from following, the onset of labour was not made. Explanations proposed for the failure to show significant maternal plasma oxytocin changes in relation to labour, included altered oxytocinase activity in maternal plasma and the lack of adequately sensitive radioimmunoassays. Few investigators at that time considered the two important issues that have rejuvenated concepts of both the role of oxytocin specifically and the regulation of parturition in general, namely variations in plasma oxytocin concentrations at different times of the 24-h day and local paracrine effects of oxylocin produced within the uterus itself.

Studies in the pregnant rhesus monkey have clearly demonstrated a pronounced $24-h$ rhythm in maternal plasma oxytocin in late gestation (Honnebier et al. 1989; Hirst et al. 1991). The increment in maternal plasma oxytocin concentration occurs exactly at the correct time to cause the switch from contractures to contractions. In addition, the peak value that occurs in the early hours of darkness increases with gestation (Hirst et al. 19.91). Similar data have been obtained in late pregnancy in pregnant women (Fuchs et al. 1992). We have recently shown that when maternal plasma oestrogen is elevated to parturient concentrations following infusion of androstenedione to the pregnant rhesus monkey at around 140 days gestation, there is an increase in the circulating maternal plasma concentration of oxytocin reaching the same levels as seen at tcrm (P. W. Nathanielsz, C. A. Mecenas, C. Umscheid and D. A. Giussani, unpublished data). In addition, although the maternal plasma oestrogen concentration remains at a constantly elevated level throughout the androstenedione infusion, maternal plasma oxytocin concentration demonstrates a 24-h rhythm with the typical rise in the early hours of darkness. It would thus appear that oestrogen acts, at least in part, by stimulating a clock mechanism, probabiy in the maternal hypothalamus.

Recent studies in the pregnant rat have shown that oxytocin is synthesized in the uterus itself (Lefebvre et al. 1992). Thus, local paracrine influences of oxytocin on prostaglandin production may not be open to evaluation from measurement of peripheral circulating oxytocin concentrations.

The oxytocin antagonist, Atosiban, inhibits the switch from contractures to contractions in the pregnant rhesus monkey (Giussani ef al. 1994). Oxytocin antagonists also inhibit the switch in pregnant baboons (Wilson et al. 1994). We have demonstrated that Atosiban inhibits premature labour induced by infusing androstenedione into the pregnant thesus monkey (Giussani et al. 1994). These studies with specific oxylocin antagonists strongly suggest that oxytocin plays a central role in the switch from contractures to contractions. Our interpretation of these data is that the maternal $24-\mathrm{h}$ clock, presumably resident within the suprachiasmatic nucleus, drives oxytocin secretion by the maternal hypothalamus in a rhythmic fashion to regulate the rhythmic switch of contractures to contractions. At term, there is an increase in the amount 
of oxytocin secreted in response to the circadian surge of activity which occurs around the hours of darkness.

We have undertaken some studies on the distribution of the oxytocin receptor mRNA in different intrauterine tissues in pregnant sheep ( $W u$ and Nathanielsz 1994). mRNA for the oxytocin receptor increases in the myometrium (Fig. 6) and endometrium during term and during cortisolinduced preterm labour but is virtually unchanged in both the mesometrium and the whole cervix ( $\mathrm{Wu}$ and Nathanielsz 1994). However, any study in vitro of the cervix must be assessed carefully as it has been shown that the oxytocin receptor is confined to the cervical epithelium and, thus, studies on the whole cervix might mask significant changes in the receptor physiology that occur in the epithelium alone (Fuchs et al. 1994).

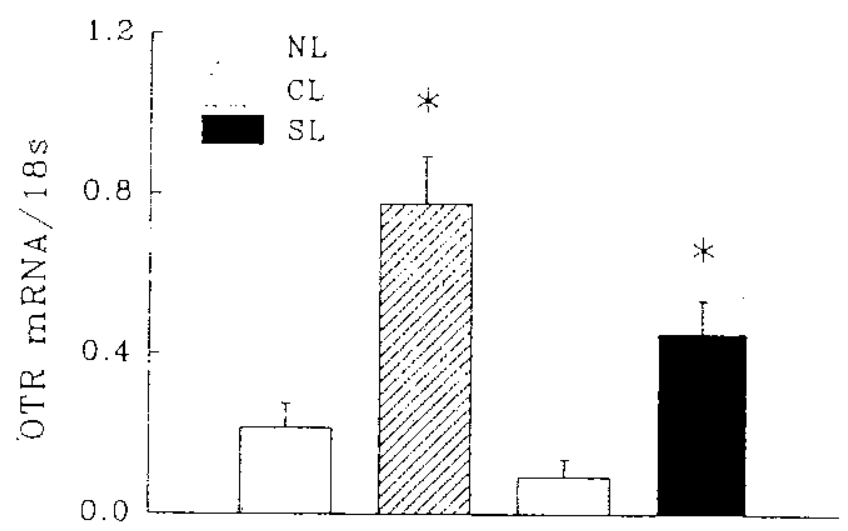

Fig. 6. Results of Northern analysis for oxytucin receptor (OTR) mRNA in myometrium laken from pregnant ewes expressed relaive io 185 mRNA in: control ewes nol in labour al 1.31 days gestation; ewes in cortisol-induced labour at 131 days gestation; and control ewes nor in labour at 140-145 days gestation and in sponlaneous labour at term. Averaged data from 6 ewes in each group, meants.e.m. $\cdot P<0.05$. NL, nol in labour; $C L$, cortisol-induced labour; SL, spontaneous babour al $1 \mathrm{erm}$.

Although there have been a large number of studies on receptor binding of oestrogen by uterine tissues (Alexandrova and Soloff 1980), few data are available on changes in oestrogen receptor (ER) gene expression immediately before and during parturition. We have quantified changes in ER mRNA in the myometrium, endometrium, mesometrium and cervix as well as in amnion, chorton, and placental cotyledon in the last third of pregnancy, during cortisol-induced premature labour and during spontaneous labour in shcep. We observed an increase in ER mRNA in the myometrium, cndometrium and corvix during both spontancous and cortisol-induced labour. ER mRNA did not increase in fetal placental cotyledon or mesometrium during either spontaneous or cortisol-induced labour. The failure of ER mRNA to increase in the mesometrium during labour in contrast to the myometrium may explain, in part, the failure of contracture-fype myometrial activity in the mesometrium to switch to contractions at labour (Wu et al. 1995), Studies on the mesometrium in the sheep provide an opportunity to study pregnancy-related changes in uterine smooth muscle in the absence of the paracrine effects of underlying decidua.

Very little information is available on the functional changes in prostaglandin receptors in any intrauterine tissues in late pregnancy. Recently, attention has been drawn to the multiplicity of receptor sites that will respond to each of the prostaglandins (Kennedy et al. 1982). For example, prostaglandin $E_{2}\left(P E_{2}\right)$ has been shown to act at four different types of receptor site in the myometrium. Two of these, the EP1 and EP3 receptor subtypes are stimulatory to myometrial contraction, whereas the EP2 and EP4 receptors are inhibitory (Senior et al, 1991). The different receptor subtypes probably utilize distinct post-receptor mechanisms. Coleman and colleagues have developed a useful classification of the various receptor subtypes and their post-receptor transduction mechanisms (see review by Senior et al. 1991). Thus, the EP1 rcceptor probably works via the inositol phosphate pathway, whereas the EP3 system decreases intracellular cyclic AMP concentrations. Both of these intracellular transduction systems will result in increased myometrial contractions. These exciting observations demonstrate the complexity of the paracrine regulatory mechanisms involved in the control of myometrial and cervical function. It is no longer adequate to simply measure the circulating concentrations, or even local concentrations, of arachidonic acid metabotites. To obtain a clear picture of the role of any regulatory factor that controls myometrial function, it is necessary to conduct a combination of studies using systems both in vivo and in vitro.

We have begun to investigate prostaglandin receptors in the myometrium in the sheep, baboun and monkey. Intraspecies and intra-tissue differences have been observed. We will focus here on our studies on EP2 receptors. We have demonstrated that AH13205, a selective EP2 agonist, will inhibit myometrial contractility in vitro in the baboon in late gestation but not in the sheep, suggesting availability of EP2 receptors in the late-pregnant baboon myometrium but not in the sheep myometrium. In the sheep, $\mathrm{PGE}_{2}$ is stimulatory indicating the presence of EPI and/or EP3 receptors, whereas the inhibitory action of $\mathrm{PGE}_{2}$ in the baboon indicates a predominance of EP2 and EP4 receptors. It is of interest that, although AH13205 causes relaxation of oxytocin-driven myometrial contraction in the pregnant rhesus monkey, $\mathrm{PGE}_{2}$ stimulates the myometrium in late pregnancy in the rhesus monkey suggesting a preponderance of stimulatory EPI and EP3 agonist receptors in the myometrium in the monkey but not in the baboon since the baboon responds to $\mathrm{PGE}_{2}$ by relaxation. 


\section{Conclusions}

When Geoffrey Thorburn began his pioneer work in the 1960s studying the fetal hypothalamo-pituitary-adrenal axis, the complexity of the regulation of parturition may not have occurred to even his eclectic mind. A thorough study of labour and delivery must now determine the roles of endocrine, paracrine, and autocrine regulators in fetal, placental, and other uterine tissues. Current knowledge, however, appears to demonstrate that both the fetus and the mother play key roles in the process of parturition. The fetus determines the duration of gestation by initiating the secretion of steroids from the fetal adrenal. These steroids, cortisol in sheep, androgens in primates, are the link to the many mechanisms that prepare the myometrium and make it possible, in the right conditions, for the switch from contractures to contractions to occur. It is the mother who, probably through her suprachiasmatic nucleus clock, contributes oxytocin as the major factor that determines the precise time of the day at which labour and delivery occur.

The new ideas that will appear over the next 30 years are also probably only dimly perceived, if at all, by any of us in the field of fetal physiology. The ultimate goal of all of these investigations has to be a better understanding of intrauterine fetal development, an ability to prevent premature labour, and a better outcome for those babies who are adversely affected by their intrauterine environment and are then born too small or too soon

\section{Acknowledgments}

We thank Karen Moore for her help with this manuscript. This work was supported by NIH grants HD 21350 and HD 26203.

\section{References}

Albrecht, E. D., and Pepe, G. J. (1990). Placental steroid hormone biosynthesis in primate pregnancy. Endocr. Rev. 11, 124-50.

Alexandrova, M., and Soloff, M. S. (1980). Oxylocin receptors and parturition. II. Concentrations of receplors for oxytocin and estrogen in the gravid and nongravid uterus at term. Endocrinology $106,736-8$.

Anderson, A. B. M., Flint, A. P. F., and Turmbull, A. C. (1975). Mechanism of action of glucocorticoids in induction of ovine parturition: effect of placental steroid metabolism. $J$. Endocrinot. 66. $61-70$.

Binienda, Z., Massmana, A., Wimsatt, J., Honnebier, M. B. O. M.. Figueroa, J. P., Reimers, T. J, and Nathanielsz, P. IF. (1989). Endocrine changes during 48 hours of food withdrawal in the pregnant rhesus monkey in the last third of gestation. J. Clin. Endocrinol. \& Metab. 68, 11848.

Buster, J. E., Ghang, R J., Preston, D. L., Elashofr, R. M. Cousins, L. M., Abraham, G. E., Hobel, C. J., and Mar. shall, J. R. (1979), Interrelationships of circulating maternal steroid concentrations in third trimester pregnancies, II. $C_{i k}$ and $\mathrm{C}_{14}$ steroids: estradiol, estriol, dehydroepiandrosterone, dehydroepiandrosterone sulfate, 5-androstenediol, 4-androstenedione, lestosierone, and dihydrotestosterone. J. Clin. Endocrinol. \& Metab, 48, 139.42 .
Challis, J. R. G. (1971). Sharp increase in free cisculating oestrogens immediately before parturition in sheep. Nature (Lond.) 229, 208.

Ducsay, C. A., Cook, M. J., Walsh, S. W., and Novy, M. J. (1983). Circadian patierns and dexamethasone-induced changes in ulerine activity in pregnant thesus monkeys. Am. J. Obster. Gynecol. 145 $389-96$.

Figueroa, J. P., Honnebier, M. B. O. M., Binienda, Z., Wimsatt, J., and Nathanielsz, P. W. (1989). Effect of 48 hour intravenous $\triangle^{4}$-androstenedione infusion on the pregnant rhesus monkey in the last third of gestation: changes in maternal plasma estradiol concentrations and myometrial contractility. Am. J. Obster. Gynecol. $161,481-6$

Fuchs, A. R., Behrens, O., and Liu, H. C. (1992). Correlation of nocturnal increase in plasma oxylocin with a decrease in plasma estradiol/progesterone ratio in late pregnancy. Am. J. Obstet. Gynecol, 167, 1559-63.

Fuchs, A. R., Chang, S. M., and Fields, M. J. (1994). Oxylocin receplors in cervical mucosa and endometrium are differently regulated during pregnancy. In 'Proceedings of the 41 st Annual Meeling of the Society for Gynecologic Investigation'. (Abstract No. P427.) (Sociely for Gynecologic Investigation: Chicago.)

Giussani, D. A., Mecenas, C. A., Jenkins, S. L., Winter, J. A., Derks, J. B., and Nathanielsz, P, W. (1994). The oxytucin antagonist Atosiban abolishes androstenedione $\left(\triangle^{4}\right.$-A)-induced, premature myometrial contractions in the chronically-instrumented rhesus monkey at 0.8 of gestation. J. Physiol. (Lond.) 483, $113 P$.

Harding, R., Poore, E. R., Bailey, A., Tbotura, G. D., Jansen, C. A. M., and Nathanielsz, P. W. (1982). Electromyographic activity of the nonpregnant sheep uterus. Am. J. Obstet. Gynecol. 142, $448-57$ -

Hirst, J. J., Haluska, G. J., Cook, M. J., and Novy, M. J. (1991). Plasma oxylocin concentrations during gestation and the effecl of an oxytocin antagonist in pregnant rhesus monkeys. Am. J. Obstet. Gynecol. 164, 252. [Abstr.]

Honnebier, M. B. O. M., Figueroa, J. P., Rivier, J., Vale, W., and Nathanielsz, P. W. (1989). Siudies on the role of oxylocin in late pregnancy in the pregnani rhesus monkey. I. Plasma concentrations of oxytocin in the maternal circulation throughout the $24 \mathrm{~h}$ day and the effect of the synthetic oxytocin aniagonist $\left.\left[1-\beta-\mathrm{Mpa}\left(\beta-\left(\mathrm{CH}_{2}\right)_{5}\right)_{1}\right) \mathrm{Me}\right) \mathrm{Tyr}^{2}$, Orn $\left.{ }^{k}\right]$ OT on spontaneous nociumal myometrial contractions. J. Dev. Physiol. (Oxf) 12 , 225-33.

Hotchkiss, J., Dierschke, D. J., Butler, W. R., Fritz, G. R., and Knobil, E. (1982). Retation between levels of circulating ovarian stcruids and pituilary gonadotropin content during the mensiruat cycle of the rhesus monkey. Biol. Reprod. 26, 241-8.

Hsu, H. W., Figueroa, J. P., Honnebier, M. B. O. M, Wentworh, R., and Nathanielsz, P. W. (1989). Power spectum analysis of myometrial electromyogram and intrauterine pressure changes in the pregnant rhesus monkey in late gestation. Am. J. Obstet. Gynecol, 161, 467-73.

Jansen, C. A. M., Krane, E. J., Thomas, A. L., Beck, N. F. G., Lowe, K. C., Joyce, P., Parr, M., and Nathanielsz, P. W. (1979). Continuous variability of felal $\mathrm{PO}_{2}$ in the chronically catheterized fetal sheep. Am. J. Obstet. Gynecol. 134, 776-83.

Kennedy, I., Coleman, R. A, Humphrey, P. P. A., Levy, G. P., and Lumley, P. (1982). Siudies on the characterization of prostanoid receptors: a proposed classification. Prostaglandins 24, 667-89.

Lanman, J. T., Mitsudo, S. M., Brinson, A. O., and Thau, R. B. (1975). Felectomy in monkeys (Macaca mulatta): retention of the placenta past normal lerm. Biol. Reprod, 12, 522-5.

Lefebvre, D. L., Giaid, A., Bennett, H., Lariviere, R., and Zingg, H. H. (1992). Oxylocin gene expression in rat uterus. Science $256,1553-5$. 
Liggins, G. C., Falrciough, R. J., Grieves, S. A., Kendall, J. Z., and Knox, B. S. (1973). The mechanism of initiation of parturition in the ewe. Recent Prog. Horm. Res, 29, 111-49.

McDonald, T. M., and Nathanielsz, P. W. (1991). Bilateral destruction of the fetal paraventricular nuclei prolongs gestation in sheep. Am. J. Obstet. Gynecol. 165, 764-70.

Mecenas, C. A., Honnebier, M. B. O. M., Owiny, J. R., and Nathanielsz, P. W. (1994). Continuous intravenous infusion of $\triangle^{4}$-androstenedione (A) to pregnant rhesus monkeys at 139 days gestational age (dGA) produces premature delivery. In 'Proceedings of the 41st Annual Meeting of the Society for Gynecologic Investigation'. [Abstract No. 13.] (Society for Gynecologic Investigation: Chicago.)

Nathanielsz, P. W. (1992). 'Life Before Birth and a Time To Be Born.' (Promethean Press: New York.)

Nathanielsz, P. W., Bailey, A., Poore, E. R., Thorburn, G. D., and Harding, R. (1980). The relationship between myometrial activity and sleep state and breathing in fetal sheep throughout the last third of gestation. Am. J. Obstet. Gynecol. 138, 65.3-9.

Nathanielsz, P. W., Honnebier, M. B. O. M., and Figuerna, J. P. (1992). In the thesus monkey placental retention after fetectomy at 12 to 130 days' gestation outlasts the normal duration of pregnancy. Am. J. Obstet. Gynecol. 166, 1529-35.

Novy, M. J., and Walsh, S. W. (1983). Dexamethasone and estradiol treatment in pregnant thesus macaques: effects on gestational fength, maternal plasma hormones, and fetal growth. Am. $J$. Obstet. Gynecol. 145, 920-31.

Novy, M. J., and Walsh, S. W. (1981). Regulation of fetoplacental steroidogenesis in rhesus macaques. In 'Fetal Endocrinology'. pp. 66-94. (Eds M. J. Novy and J. A. Resko.) (Academic Press: New York.)

Patrick, J., Challis, J., Campbell, K., Carmichael, L., Natale, R., and Richardson, B. S. (1980). Circadian rhythms in maternal plasma cortisol and estriol concentrations at 30 to 31,34 to 35 , and 38 to 39 weeks' gestational age. Am. J. Obstet. (iynecol.
136, 325-34.

Pepe, G. J., and Albrecht, E. D. (1990). Regulation of the primate fetal adrenal cortex. Endocr. Rev. 11, 151-76.

Senior, J., Marshall, K., Sangha, R., Baxter, G. S., and Clayton, J. K. (1991). In vitro characterization of prostanoid EP-receptors in the non-pregnant human myometrium. Br. J. Pharmacol. 102,
$747-53$.

Sheldrick, E. L., and Flick-Smith, H. C. (1993). Effect of ovarian hormones on oxytocin receptor concentrations in explants of uterus from ovariectomized ewes. J. Reprod. Ferit. 97, 241-5.
Soloff, M. S., Fernstrom, M. A., Periyasamy, S., Soloff, S., Baldwin, S, and Wieder, M. (1982). Regulation of oxylocin receptor concentration in rat ulerine explants by estrogen and progesterone. Biochem. Cell Biol. 61, 625-30.

Taylor, N. F., Martin, M. C., Nathanielsz, P. W., and SerónFerre, M. (1983). The fetus determines circadian oscillation of myometrial electromyographic activity in the pregnant rhesus monkey. Am. J. Obstet. Gynecol. 146, 557-67.

Theobald, G. W. (1969). Oxytocin reassessed. Obstet. Gynecol. Surv $23,109-3$ ?

Van Wagenen, G., and Newton, W. H. (1943). Pregnancy in the monkey after removal of the fetus. Surg. Gynecol. Obstet. 77, $539-43$.

Walsh, S. W., Ducsay, C. A., and Novy, M. J. (1984). Circadian hormonal interactions among the mother, fetus and amniotic fluid. Am. J. Obstet. Gynecol. 150, 745-53.

Wilson, L., Parsons, M. T., and Flouret, G. (1991). Forward shift in the initiation of the nociurnal estradiol surge in the pregnant baboon: is this the genesis of labor? Am. J. Obstet. Gynecol. 165, 1487-98.

Wilson, L. Jr, Pak, S. C., Santolava, J, and Parsons, M. (1994). Induction of estradiol synthesis and noctumal uterine contractions by dehydroepiandrosterone and their inhibition by an aromatase inhibitor. In 'Proceedings of the 4lst Annual Meeting of the Society for Gynecologic Investigation'. [Abstract No. 14.] (Society for Gynecologic Investigation: Chicago.)

Wu, W., and Natbanielsz, P. W. (1994). Changes in oxylocin receptor messenger RNA in the endometrium, myometrium, mesometrium, and cervix of sheep in late gestation and during spontaneous and cortisol-induced labor. J. Soc. Gynecol. Invest. 1, 191-6.

Wu, W. X., Myers, D. A, and Nathanielsz, P. W. (1995). Changes in estrogen receptor mRNA in sheep fetal and maternal tissues during late gestation and labor. Am. J. Obstet. Gynecol. 172,
844-50.

Zhang, J., Weston, P. G., and Hixon, J. E. (1991). Influence of estradiol on the secretion of oxytocin and prostaglandin $F_{20}$ during luteolysis in the ewes. Biol. Reprod. 45, 395-403.

Manuscripl received 13 October 1994; revised and accepled 13 June 1995 